
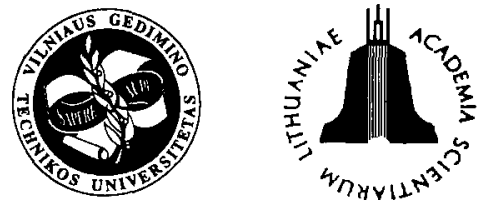

\title{
CONCRETE MIX TRANSPORTATION MODELLING
}

\author{
Edwin Koźniewski ${ }^{1}$, Zygmunt Orlowski ${ }^{2}$ \\ Institute of Civil Engineering, Biatystok University of Technology \\ ul. Wiejska 45E, 15-351 Biatystok, Poland
}

Received 05 Aug 2002; accepted 09 Jan 2003

\begin{abstract}
The paper presents the simulation model of concrete mix transportation process in the system - batching centre - a number of construction sites. An essential part of the analysed model is a multi-phase system of queues which emerge in concrete transportation characterised by: waiting time for loading, waiting for discharge, the distances from the plant to construction sites, the number and type of truck mixers used, the types of transport means for on-site deliveries, transportation costs. The paper also includes an example solved with a computer program designed on the basis of an algorithm formulated in the model.
\end{abstract}

Keywords: modelling of process, simulation, transportation

\section{Introduction}

This paper develops a simulation approach to the study of transport mix operations. The study provides the predicting of system production and defining the optimum number of truck mixers and their kinds. It includes the designing of a model of dependence between: the size of queues that appear while concrete mix is loaded onto transport vehicles, trucks unloading when they reach their destination and the amount, type of truck mixers used, the order of their introduction into realizing the process, and transport costs.

Making a concrete mix and its delivery to the placement site is one of the most important processes of concrete works sequence. The process consists of the following operations: preparing the concrete mix, loading it onto a transport vehicle, transporting it to its destination (external transport) and transporting the mix to the construction site (internal transport).

Remote transport of concrete mix is usually performed in truck mixers which ensure a good quality of concrete mix delivered to the construction site. On the Polish market there are companies which offer truck mixers of varied capacities: from $2 \mathrm{~m}^{3}$ to $9 \mathrm{~m}^{3}$; at present truck mixers which hold up to $13 \mathrm{~m}^{3}$ of concrete are also produced [1]. Using the latter type of truck mixers is not common due to a limited wheel load capacity of roads, bridges and overpasses. The internal transport on a building site usually includes two kinds of machines: concrete pumps or crane containers. The task model presented in the paper enables to establish the most effective set of concrete mixers for concrete transport in the course of complex construction processes, ie the cases when the transport operates on several sites at the same time, using transport machines of different capacity.

Selecting the set of trucks for concrete transport is often assumed that the duration of the discussed process has determinist values $[2,3]$. In the suggested formulas the delays resulting from traffic problems are considered through the use of appropriate coefficients.

The question of concrete mix transport and the analysis of the designed systems operation (selection of vehicles, the analyses of sets capacity) closely resembles the problems analysed by the theory of mass service. There is a number of sources which discuss the application of queuing theory to describe the phenomena associated with transport in engineering and building industries [4-6]. A very interesting study of concrete production plants and concrete mix transport was presented by Halpin with his team [7]. In the designed simulation model, the duration of concrete mix transport to the construction site as well as the times of return to the production plant were described with regressive function. The authors analysed the interrelationship of realisation time, costs, the amount of transported concrete mix for selected distances and required sets of trucks (TCQ - Time - Cost Quantity).

However, the practice of concrete works indicates more complex situations where the models described in literature cannot be applied. It involves, among others, the case when we have truck mixers of different loadcapacities at our disposal (trucks of different load-capacities usually have a different distribution of loading and unloading probability time) and when one and the same 
concrete production plant supplies a number of construction sites at the same time.

The process in question has three essential time restrictions:

- the time between the concrete mix production and its placing is limited and cannot exceed the set value;

- time gap between placing (forming) a particular portion of concrete in the structure and delivery of next portion cannot exceed the set value;

- the pump which delivers the concrete mix cannot have too long stops.

The model presented here (subsequently support system) will also include random times of particular operations the discussed process consists of.

In literature the question of concrete mix transport, closely related to the queuing theory has been extensively described in the form of analytical and simulation models [8-12]. However, the practice of concrete works involves more complex situations, where the described models might appear to be of a very little use. It is the case when one has truck mixers of different load-capacities (trucks of different load-capacities usually have different probability time distribution of loading and unloading) and one and the same concrete mix production plant supplies many construction sites at the same time.

The problem in question has two vital constraints:

- the time between the moment the mix is produced and the moment it is placed is limited,

- standing time of the pump which discharges concrete mix must not be too long.

The model described here will consider a randomtype time of particular operations the analysed system is made up of.

The suggested model of concrete mix transport belongs to a wide class of DSS application in construction and management in civil engineneering $[10,11,13,14]$.

In the presented model, the criterion for the optimum solution is minimal cost. This criterion can be used alongside other factors of solution assessment. The problem of multi-criterion function of purpose has been discussed in depth in a number of papers $[6,11,15]$.

\section{Technological conditions of the process}

The significance of the discussed process results from the fact that the quality of any operation (preparing the mix, remote transport, transport within the construction site, placing the mix) has a direct influence on the final effect: on concrete's strength and durability [16].

The major concrete mix plants own permanent laboratories and due to quality control of particular components of the mix and the control of the procedures of mix production technological process are able to ensure a high quality of their product.

Concrete mix delivered to a construction site should have the same consistency as designed for this particular structure. The best transport conditions are ensured when truck mixers are used. The essential factor in the process of concrete mix transport is the process duration. The time from the moment of mix preparation to the moment of placing under particular conditions is strictly defined and should be shorter than the time of concrete set. That time directly determines the distance which can be covered for transporting mix. When the expected time of mix transport is shorter than the admission time ( $\left.t^{\mathrm{adm}}\right)$ all the components are mixed in plant's central mixer and while it is transported in the truck mixer, the slowly revolving mixer drum is only supposed to prevent the transported mix from segregating. If it is necessary to transport the concrete over a considerable distance (the transport takes longer than the admission time), then the components are prepared in the plant's central mixer, while mixing takes place in the truck mixer on its way to the construction site or directly before it is unloaded. However, in such a case the capacity of the mixer drum is used in $50-60 \%$, while in the other case, when components are mixed in the central mixer, it is used in $80 \%$.

In large urban areas, crucial factors which affects transport time is the volume of traffic associated with the time of day $\tau$. During rush hours - due to traffic the transport time may be so long that it exceeds the value of $t^{a d m}$ (concrete set value). As a result, concrete placing at customer $k$ becomes impossible. Therefore, it appears necessary to investigate the dependence $t_{\text {tran }}$ of total transport time of concrete mix to a construction site on the time of day $\tau$. The value of $t_{\text {tran }}$ depends on the intensity of traffic $R(t)$ (the intensity of traffic $R(t)$ is determined as the limit $\lim _{\Delta t \rightarrow 0} \frac{N(t+\Delta t)-N(t)}{\Delta t}$, where $N(t)$ stands for the number of cars passing the investigated section of the road at time $\tau$. In practice, the mean value intensity of traffic is determined by $R_{s, r}(t)=$ $N(t+\Delta t)-N(t)$

$\Delta t$

a concrete mixing plant to a customer $k$. Then, the total transport time of concrete mix is determined by $T(\tau)$ function, depending on the day time. In order to determine the most suitable time of day, or more precisely, the length of time required, to place concrete mix which starts at a particular time of day, the section of road is considered $<\tau, \tau+\Delta \tau_{k}>$ at which $T(\tau)<<t^{a d m}$. The problem of traffic flow was discussed in the paper [17] which presents the methods of quality analysis, the optimum quantity and the optimum planning of public passenger transport stops.

The transport of concrete mix on the construction site is generally complex: apart from moving the mix horizontally, it is also necessary to move it vertically. At present, there are two methods of concrete mix transport: in containers with cranes and with concrete pumps. The first type - by containers with cranes - is used on construction sites where there is a little demand for concrete and in case of a slow pace of concrete placing. English sources [18] indicate that transport in containers 
with cranes is applied when concrete is placed at 8 to $12 \mathrm{~m}^{3} /$ hour. Pump transport is applied above all on construction sites where a quick pace of concrete placing is required. At present it is a commonly used form of onsite transport at sites where monolithic technology is applied. The main advantages of using this type of transport are: the option of reaching any spot of the concrete structure, a considerable reach both vertically and horizontally, continuity of concrete placing, adjustable capacity. Besides, the pump transport has a positive effect on the quality of concrete - the mix which has been properly designed does not undergo segregation, and as a result of using pumps, the density of the mix is increased which, in turn, results in the rise of concrete strength by as much as $10 \%[8,19]$. Due to technological reasons the process of pumping should be continuous. That's why it is crucial to ensure the continuity of concrete mix supply.

\section{Model building}

Model input data are:

1. The information concerning the customers:

- the demand for concrete mix from individual customers $\left(\mathrm{m}^{3}\right)$,

- collection sites for concrete mix (the distance, road types, wheel load capacity of roads, bridges and overpasses),

- the rate of laying the concrete mix (depending on the type of cemented structure and the type of concrete mix at the site.

2. The information concerning the transport provider the concrete mix production plant:

- capacity of the batching centre

- the type of truck mixers,

- the number of truck mixers within each type.

Constraints of the model:

- the total time of remote and local transport of concrete mix is shorter than the admission time - the time of concrete set $\left(t^{a d m}\right)$,

- a pause in concrete placing in the formed element, as a result of waiting for another portion of concrete, is shorter than admission time $\left(t^{\text {tech }}\right)$,

- the pump's standing time on the construction site is shorter than the admission time $\left(t^{\text {pump }}\right)$ - the time which guarantees proper performance of transport vehicle,

- road capacity constraint; concrete mix can be carried to the construction site by a vehicle of certain load-capacity ( $x$ variable of transport vehicle $i$ selection options has three values: $x_{i j k} \in\left\{1, \frac{1}{2}, 0\right\}$, where 1 - the vehicle can be used, $\frac{1}{2}$ - it can be used, provided the route is altered, usually longer route is suggested, 0 - it cannot be used),

- the rate of discharge is limited - depending on the type of construction elements where concrete is to be placed,

- the truck mixers' capacities have an obvious effect on the time of discharge (mixers of large capacity require longer discharge time and consequently the transport cycle is longer),

- the duration of concrete-placing process (the time of concrete mix delivery) at recipient $k$ cannot exceed the time defined in the contract.

According to the accepted method of model building, the transport process and concrete mix placing process, in relation to the transport vehicle, is made up of the following operations:

- loading the concrete mix at the concrete-mixing terminal,

- transport of concrete mix to the supply point at the construction site,

- waiting for a discharge in a queue,

- local transport and concrete mix placing,

- the return of a vehicle to take another load of concrete mix,

- waiting in a queue for concrete mix loading.

Let's assume the following notation for truck mixers, their routes and recipients:

$i$ - truck mixer's number,

$m-$ the number of truck mixers,

$j$ - the number of truck mixer's current delivery,

$j_{k}$ - the number of truck mixer's current delivery to recipient $k$,

$n_{i}-$ the number of deliveries of a truck mixer,

$k$ - recipient's number,

$l$ - the number of recipients,

and the notation of times for the following:

$\alpha_{i j k}$ - loading the truck mixer $i$ for delivery $j$ and recipient $k$,

$\beta_{i j k}$ - trips of the truck mixer $i$ to the construction site for delivery $j$ to recipient $k$,

$\gamma_{i j k}$ - truck mixer $i$ waiting for a discharge during delivery $j$ for recipient $k$,

$\delta_{i j k}-$ placing concrete mix from truck mixer $i$ during delivery $j$ for recipient $k$,

$\varepsilon_{i j k}$ - a trip back of a truck mixer $i$ (to the terminal) during delivery $j$ from recipient $k$,

$\chi_{i j k}$ - a truck mixer $i$ waiting for loading during delivery $j$ for recipient $k$.

Further variables are as follows: $z_{i j k}=\beta_{i j k}-\alpha_{i j k}$,

$j_{i j k}=\gamma_{i j k}-\beta_{i j k}$,

$w_{i j k}^{\prime}=\delta_{i j k}-\gamma_{i j k}$,

$w_{i j k}=\varepsilon_{i j k}-\delta_{i j k}$,

$p_{i j k}=\chi_{i j k}-\varepsilon_{i j k}$

$z_{i j k}^{\prime}=\alpha_{i, j+1 . k}-\chi_{i j k}$

The above describe the following: the time of concrete mix loading $\left(z_{i j k}\right)$, trip time $\left(j_{i j k}\right)$, waiting for discharge (placing) of concrete mix $\left(w_{i j k}^{\prime}\right)$, duration of con- 
crete mix discharge $\left(w_{i j k}\right)$ duration of the trip back from the construction site $\left(p_{i j k}\right)$, waiting for loading the concrete $\operatorname{mix}\left(z^{\prime}{ }_{i j k}\right)$ for $i \in\{1,2, \ldots, m\}, j=1,2, \ldots, n_{i}$, $k \in\{1,2, \ldots, l\}$ the process can be shown with a functional sequence $f_{i}\left(t, z_{i j k}, j_{i j k}, w^{\prime}{ }_{i j k}, w_{i j k}, p_{i j k}, z^{\prime}{ }_{i j k}\right)$ (or $f_{i}\left(t, \alpha_{i j k}, \beta_{i j k}, \gamma_{i j k}, \delta_{i j k}, \varepsilon_{i j k}, \chi_{i j k}\right)$ ) of function of time $t$ (with parameters $\alpha_{i j k}, \beta_{i j k}, \gamma_{i j k}, \delta_{i j k}, \varepsilon_{i j k}, \chi_{i j}$ which depend on time $t$ and change according to the index system $(i, j, k)$ which describe the concrete mix transport and placing process in relation to a particular vehicle:

$$
\begin{aligned}
& f_{i}\left(t, \alpha_{i j k}, \beta_{i j k}, \gamma_{i j k}, \delta_{i j k}, \varepsilon_{i j k}, \chi_{i j k}\right)= \\
& \left\{\begin{array}{lrrr}
a_{k} & \text { dla } & \alpha_{i j k} \leq t<\beta_{i j k}, \\
& \gamma_{i j k}-t & \text { dla } & \beta_{i j k} \leq t<\gamma_{i j k}, \\
{ }_{k} & \gamma_{i j k}-\beta_{i j k} & \text { dla } & \gamma_{i j k} \leq t<\delta_{i j k}, \\
0 & & \text { dla } & \delta_{i j k} \leq t<\varepsilon_{i j k}, \\
0 & & \text { dla } & \varepsilon_{i j k} \leq t<\chi_{i j k}, \\
a_{k} & t-\varepsilon_{i j k}-\varepsilon_{i j k} & \text { dla } & \chi_{i j k} \leq t<\alpha_{i+1, j k} . \\
a_{k} & &
\end{array}\right.
\end{aligned}
$$

Note that only $j$ index has ascending values in the process. Not all index systems $(i, j, k)$ will be presented in the process, that will depend on the ternary variable $x_{i j k}$ which assumes values from the set $\left\{1, \frac{1}{2}, 0\right\}$ as stated in the previously described model.

The above sequence is shown in Fig 1 which contains three combined systems of coordinates and three plots which illustrate the concrete mix transport and placing process in reference to a transport vehicle in time $t$.

The top chart shows the function describing transport in vehicle 1: in the first cycle the mix is carried to recipient 1 , in the second cycle to recipient 2 , in the

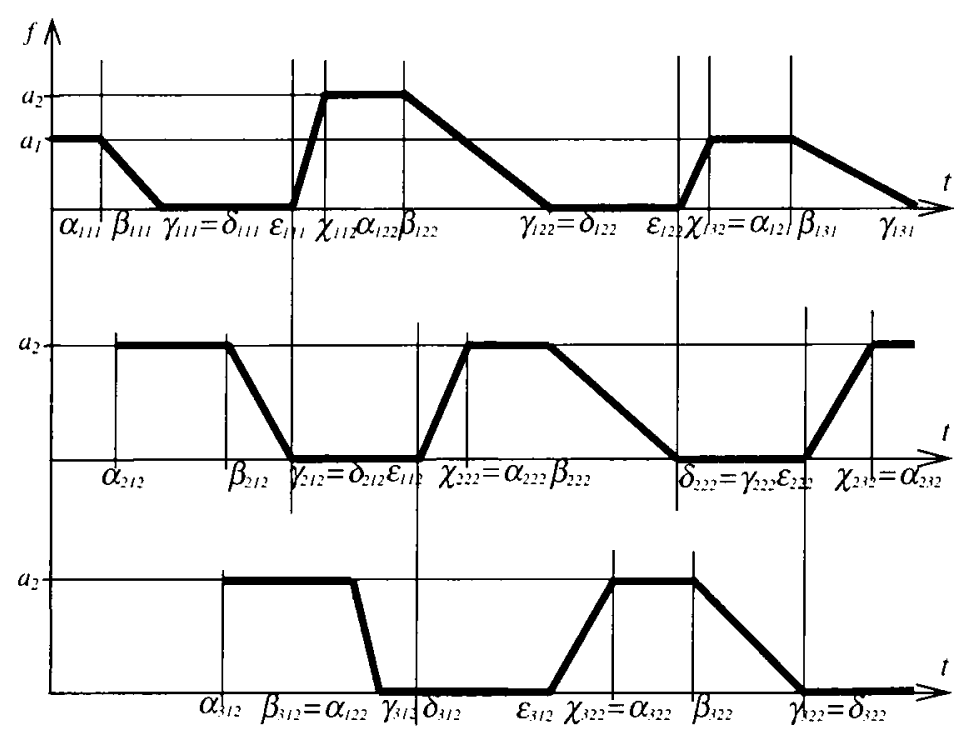

Fig 1. Three plots illustrating the process of transport and placing of concrete mix using three vehicles in time $t$ to two recipients third cycle again to recipient 1 . The chart in the middle shows the function which describes transport in vehicle 2 : in the first and second cycle the mix is delivered to recipient 2 , the third cycle has started. The chart at the bottom shows the function which describes transport in vehicle 3 in two incomplete cycles. Note that vehicle 1 during the second delivery is waiting for loading $\left(\chi_{112}<\alpha_{312}=\alpha_{122}\right)$, vehicle 3 during the first delivery is waiting for vehicle 2 to unload during its first delivery $\left(\gamma_{312}<\varepsilon_{212}\right)$.

The top horizontal part of the diagram shows: the vehicle is likely to wait in a line for loading and unloading, the bottom horizontal part of the diagram means: a vehicle is likely to wait for unloading and placing of concrete mix, the diagonal 'rising' line shows the vehicle's trip from the concrete mixing plant to the construction site, the diagonal 'falling' line means the vehicle's trip from the construction site to the concrete mixing plant.

Let's assume the following notation:

$\omega_{i j k}$ - the volume of the load transported by truck mixer $i$ during trip $j$ to recipient $k$,

$\omega_{k}$ - the demand from recipient $k$ for concrete mix,

$\tau_{k}$ - the total time required to complete concrete mix placing at recipient $k$, considering the selected set of vehicles,

$v_{i}$ - the truck mixer's load capacity,

$c_{i}$ - labour cost of truck mixer's one machine-hour.

With the assumed notation the equation $\omega_{i j k}=v_{i}$ takes place. In order to define the size of demand $\omega_{k}$ from recipient $k$ we'll introduce the value of task's completion of concrete mix transport to that recipient $r_{k}\left(j_{k}\right)=\sum_{j \leq j_{0}} \bar{\omega}_{i j k} \quad\left(j_{k}\right.$ index is understood as a pair $\left.(j, k)\right)$ during concrete mix deliveries and limit value $j_{k}{ }_{k}$ described in the following way $r_{k}\left(j_{k}^{g}\right) \leq \omega_{k}$ and $r_{k}\left(j{ }_{k}+1\right)>\omega_{k}$. Then, the recipient $\mathrm{k}$ is satisfied and the transport of concrete mix to construction site $k$ is no longer required. The time of concrete placing at recipient $k$ is shown as follows:

$$
\tau_{k}\left(j_{k}^{g}\right)=\sum_{j_{k} \leq j^{\prime \prime} k}\left(w_{i j k}^{\prime}+w_{i j k}\right) .
$$

After the length of time $\tau_{k}\left(j^{g}\right)$ the number of recipients decreases by one, while the means of transport do not change. In such circumstances one ought to establish new distribution of truck mixers to provide service to other $(k-1)$ recipients.

The solution to the question of selection of a set of truck mixers for a particular recipient (a construction site) involves finding the minimum of the function

$$
K_{k}=\sum_{(i, j, k) \in I_{k}}\left(z_{i j k}+j_{i j k}+w_{i j k}^{\prime}+w_{i j k}+p_{i j k}+z_{i j k}^{\prime}\right) \cdot c_{i}
$$


in set $I_{k}$ with conditions:

$$
\begin{gathered}
j_{i j k}+w_{i j k}^{\prime}+w_{i j k} \leq t^{u d m}, \\
w_{i j k}^{\prime}<t^{p u m p}, \\
w_{i j k}^{\prime}<t^{\text {eech }}, \\
\tau_{k}=\sum_{(i, j, k) \in I^{k}}\left(w_{i j k}^{\prime}+w_{i j k}\right) \leq \tau_{k}^{a d m},
\end{gathered}
$$

where $t^{\text {ddm }}$ stands for admission time of concrete mix transport, $t^{\text {pump }}$ stands for the admission standing time of a pump on a construction site, $t^{\text {pech }}$ - the admission time between placing of $j_{k}-t h$ concrete mix is completed and before placing the next portion $\left(j_{k}+1\right)$ starts. The description of set $I_{k}$ is as follows. The minimum of function $K_{k}$ is calculated in relation to the system of three indexes $(i, j, k)$ with rising $j$ and $k$ is fixed. In fact it is a system of $i$ indexes, ie the way (order) to set numbers to truck mixers. The sequence $((1,1,2)$, $(3,2,2),(2,3,2),(1,4,2),(3,5,2),(1,6,2),(2,7,2))$ means that transport was provided to construction site $2(k=2)$, there were $7\left(j_{2}{ }^{8}=7\right)$ trips, truck mixers $1,2,3$ were used in the following order $(1,3,2,1,3,1,2))$. Thus, $I_{k}$ is a set of all systems $\left\{\left(\left(i_{1}, 1, k\right),\left(i_{2}, 2, k\right), \ldots,\left(i_{h}, h, k\right)\right)\right\}$, where $i \in\{1,2, \ldots, m\}, s=1,2, \ldots, h$.

Optimisation of the problem, in case of concrete mix production plant, must be extended to all $l$ recipients. Then, one ought to assume function $K$ as the ultimate objective function being the sum of function $f_{k}$, ie $K=\sum_{k=1}^{l} K_{k}$, while the set of possible solutions $I=\bigcup_{k=1}^{l} I_{k}$ Then, the task involves finding

$$
\left.\min _{(i, j, k) \in I} \sum_{k=1(i, j, k) \in I_{k}}^{l} \sum_{i j k}+j_{i j k}+w_{i j k}^{\prime}+w_{i j k}+p_{i j k}+z_{i j k}^{\prime}\right) \cdot c_{i}
$$

with conditions (4)-(6).

\section{The description of problem solution algorithm}

In order to avoid standing times on the placement site and the batching centre, the values $\beta_{i j k}, \chi_{i j k}, \varepsilon_{i j k}, \gamma_{i j k}$ ought to be selected in such a way that $\varepsilon_{i_{1} j_{1} k_{1}}=\gamma_{i_{2} j_{2} k_{2}}$ (the placement site) and $\chi_{i_{2} j_{2} k_{2}}=\beta_{i_{1} j_{1} k_{1}}$ (the batching centre) At the beginning of the process that's $j_{1}=j_{2}$, $i_{2}=i_{1}+1, k_{1}=k_{2}$, under the supposition that the sequences $i_{1}, i_{2}, \ldots, i_{m}, j_{1}, j_{2}, \ldots, j_{n}$, are ascending. Then standing is excluded. Achieving such a system of values is practically impossible. While building a model we must assume work priorities - which action has the priority: loading the truck mixers or placing the mix on the construction site? If we assume for obvious reasons that placing the mix has the priority, and the inequality $z_{i j k}<w_{i j k}$, takes place, then although the plant's working time will not be used fully but we'll ensure meeting the technological requirements defined in the conditions which restrict placing the concrete mix (even if there is a queue $\left.\gamma_{i_{2} j k}<\varepsilon_{i_{1} j k}\right)$.
In determinist case, the variables $\beta_{i j k}, \chi_{i j k}, \varepsilon_{i j k}, \gamma_{i j k}$, assume constant values of time, calculated through chronometric tests. The problem is solved by assuming initially any variation $\left(i_{1}, i_{2}, \ldots, i_{m}\right)$ of vehicles' order and the variation $\left(k_{1}, k_{2}, \ldots, k_{l}\right)$ of order of customers' (construction sites') servicing. The sequence of concrete mix delivery realisation is created in the following way: the first realisation has the form $\left(i_{1}, j_{k_{i}}, k_{1}\right)$, the $\operatorname{second}\left(i_{2}\right.$, $j_{k_{2}}, k_{2}$ ), where $j_{k_{i}}=1, j_{k_{2}}=1$. Note that the initial $l$ realisations do not need to refer to all 1 customers (in other words, in the initial $l$ realisations not all the values $\left(k_{1}, k_{2}, \ldots, k_{l}\right)$ need to appear). One or a few customers might 'wait' while other construction sites are being cemented. The number of trips $j_{k_{i}}$ of truck mixers to a customer $k_{i}$ (the second in a group of three) goes up until the required amount of concrete mix is delivered to a construction site $k_{i}$. The change of the number $j_{k_{i}}$ occurs when the value $k_{i}$ 'returns' in the sequence of realisation (the third in a group of three which indicates the realisation). More specifically, when the realisation $\left(i_{u,}, j_{u,}, k_{u}\right)$ shifts to $\left(i_{,}, j_{1}, k_{v}\right)$ the number of trips to customer $k_{v}$, the value $j_{v}-1$ becomes $j_{v}$. After the condition of satisfying each customer $1,2, \ldots, l$ is met, the complete sequence $I$ of realisation is created. The value of $K$ function is calculated along with the value of $K_{k}$ function for $k=1,2, \ldots, l$. The procedure is repeated until all the options of creating a sequence of realisation are used.

In practice, however, random occurrences will be dealt with. Then, determinist variables defined above $\alpha_{i j k}$, $\beta_{i j k}, \gamma_{i j k}, \delta_{i j k}, \varepsilon_{i j k}, \chi_{i j k}$, and at the same time variables $z_{i j k}$, $j_{i j k}, w_{i j k}^{\prime}, w_{i j k}, p_{i j k}, z^{\prime}$, become random variables of definite distribution. Then, in the model (and in a computer program) the input data will be mean values of random variables and actual values of times will be generated by the program in accordance with random number generators.

Fig 2 shows a block graph of problem solution.

While solution algorithms for such problems are designed, very often certain simplifications are used, which are the result of experiments and tests conducted at construction sites.

The conditions encountered in reality reduce the size of the model, making it easier to conduct numerical realisation in the computer program.

In particular, in a real-life situation, three truck mixers are used which can hold up to $4,5 \mathrm{~m}^{3}, 6,0 \mathrm{~m}^{3}$ and $9 \mathrm{~m}^{3}$. follows:

The order of actions while selecting vehicles is as

- finding out which vehicles can be used considering the load-capacity of roads and bridges;

- deciding whether the rate of discharge is not too slow for vehicles of big capacity (they could be ruled out due to technical requirements. For instance, during the local transport of concrete mix using containers (cranes) the discharge of a vehicle of $9 \mathrm{~m}^{3}$ capacity approximately takes up to $120 \mathrm{~min}$; 


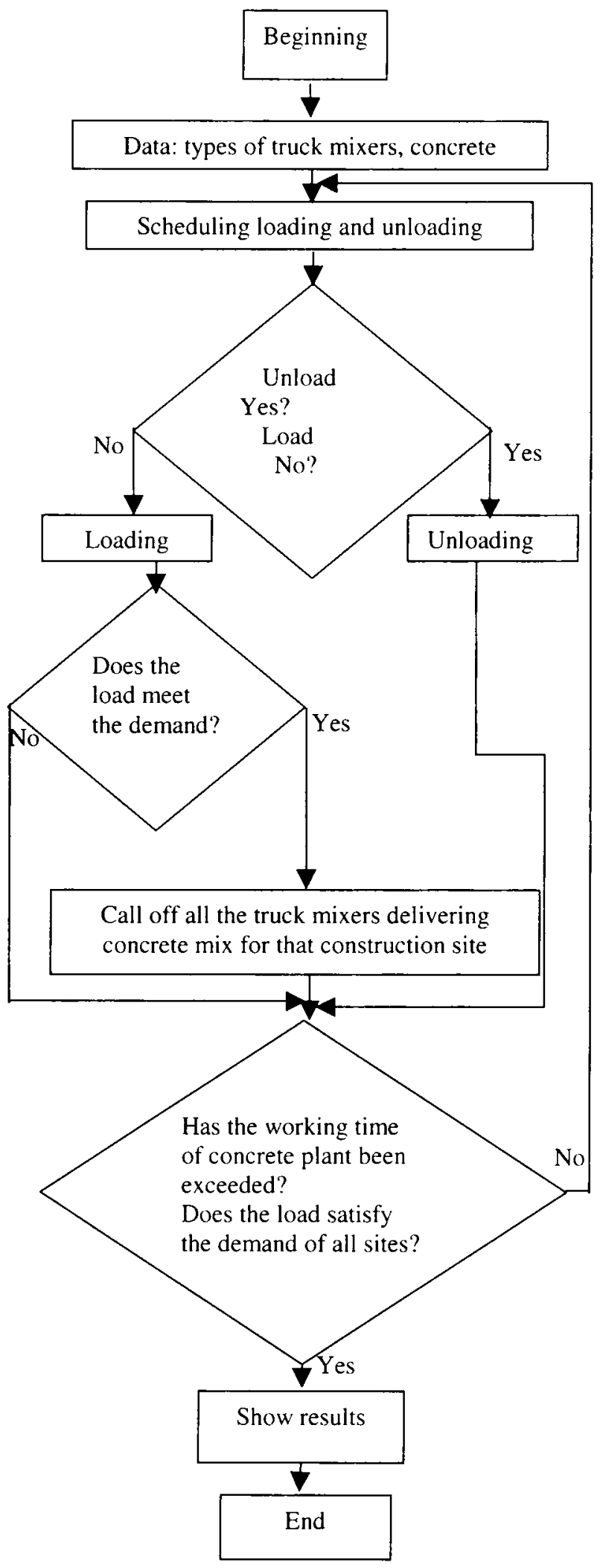

Fig 2. Block diagram of simulation program the vehicles of the biggest capacity are used for the longest distances.

\section{Example}

A concrete plant is supposed to deliver on a particular day $96 \mathrm{~m}^{3}$ of concrete mix to a construction site $\mathrm{B}_{1}-w_{1}=96 \mathrm{~m}^{3}$ and $w_{2}=67 \mathrm{~m}^{3}$ to a construction site $\mathrm{B}_{2}$. The distance between the construction sites and the concrete plant is respectively: $d_{1}=7,5 \mathrm{~km}$ and $d_{2}=12 \mathrm{~km}$. The plant owns two truck mixers of capacity $v_{1}=7 \mathrm{~m}^{3}$ and four truck mixers of $v_{2}=4 \mathrm{~m}^{3}$ for remote transport. Due to the quality of roads leading to the construction site $B$ transport can be conducted with truck mixers of capacity which does not exceed $V_{2}=4 \mathrm{~m}^{3}$. The average rate of concrete mix placing on construction site $B_{1}$ is $0,25 \mathrm{~m}^{3} / \mathrm{min}$, while on construction site $B_{2}$ it is $0,33 \mathrm{~m}^{3} / \mathrm{min}$. The allowed transport time of concrete mix in particular conditions is $t^{a d m}=90 \mathrm{~min}$. Such a set of vehicles should be selected which guarantees delivery of the required amount of mix while standing times should be as short as possible, taking into account all the constraints. Besides, all the technical requirements set for the concrete mix transport must be met.

The data for computer program is in Table 1.

Table 1. Input data

\begin{tabular}{c|c|c|c|c|c|c}
\hline $\begin{array}{c}\text { Truck } \\
\text { number }\end{array}$ & $\begin{array}{c}\text { Truck } \\
\text { mixer } \\
\text { capaçity } \\
(\mathrm{m})\end{array}$ & $\begin{array}{c}\text { Loading } \\
\text { time } \\
\text { (min) }\end{array}$ & $\begin{array}{c}\text { Time of } \\
\text { journey to a } \\
\text { consmuction } \\
\text { site (min) }\end{array}$ & $\begin{array}{c}\text { Unloading } \\
\text { time } \\
\text { (min) }\end{array}$ & $\begin{array}{c}\text { Return } \\
\text { trip time } \\
\text { (min) }\end{array}$ & $\begin{array}{c}\text { Reci- } \\
\text { pients } \\
\text { number }\end{array}$ \\
\hline 1 & 7 & 9 & 20 & 21 & 15 & 1 \\
\hline 2 & 7 & 9 & 20 & 21 & 15 & 1 \\
\hline 3 & 4 & 7 & 20 & 12 & 15 & 1 \\
\hline 4 & 4 & 7 & 24 & 20 & 21 & 2 \\
\hline 5 & 4 & 7 & 24 & 20 & 21 & 2 \\
\hline 6 & 4 & 7 & 24 & 20 & 21 & 2 \\
\hline
\end{tabular}

The above task was solved with a specially designed computer program whose scheme diagram is shown below (Fig 2). After conducting computer simulation, it was established that the most effective order of truck mixers loading is as follows: $3,4,5,1,2,6$. Other results are shown in Table 2.

Table 2. The results of computer analysis

\begin{tabular}{c|c|c|c|c}
\hline $\begin{array}{c}\text { Truck } \\
\text { number }\end{array}$ & $\begin{array}{c}\text { Number of } \\
\text { trips (unit) }\end{array}$ & $\begin{array}{c}\text { Waiting for } \\
\text { loading (min) }\end{array}$ & $\begin{array}{c}\text { Waiting for } \\
\text { unloading } \\
\text { (min) }\end{array}$ & $\begin{array}{c}\text { Volume of } \\
\text { deliverę mix mix } \\
\left(\mathrm{m}^{3}\right)\end{array}$ \\
\hline 1 & 6 & 0 & 5 & 42 \\
\hline 2 & 5 & 23 & 5 & 35 \\
\hline 3 & 5 & 12 & 53 & 20 \\
\hline 4 & 6 & 0 & 0 & 24 \\
\hline 5 & 6 & 4 & 4 & 24 \\
\hline 6 & 5 & 7 & 14 & 20 \\
\hline
\end{tabular}




\section{Conclusions}

The presented algorithm enables to analyse fully the state of all participants of the process: it defines the working time of particular trucks, their loading and unloading queuing times. Besides, it defines the truck mixer's time effectiveness coefficient (work and standing times). The final effect of the analysis are economic indicators of the assumed solution expressed as price per unit: preparation and transport of $1 \mathrm{~m}^{3}$ of concrete mix to a construction site $\left(P L N / \mathrm{m}^{3}\right)$. The discussed algorithm also defines the optimum order of loading truck mixers which will ensure the shortest time of task completion, thus the most effective economic indicators of the selected set of vehicles.

The article was prepared as a part of project: $\mathrm{W} / \mathrm{IIB} / 6 / 00, \mathrm{~W} / \mathrm{IIB} / 5 / 0 \mathrm{I}$.

\section{References}

1. Wolfram A. Vom Handbetrieb zur Hochtechnologie im Betonbau - 100 Jahre. Entwicklung in der Baumaschinentechnik. Beton- und Stahlbetonbau, 94, 1999, p. 41-52.

2. Skarżyński A. Technological and organizational principles of the realisation of the multistory monolithic concrete building in the climbing forms. Wydawnictwo Politechniki Poznańskiej, Poznań, 1992 (in Polish).

3. Szwabowski J. Betonowanie pompami. Cement Polski, No 4 (12), p. 22-23 (in Polish).

4. Siudak M. Research operation. Oficyna Wydawnicza Politechniki Warszawskiej. Warszawa, 1994. 358 p. (in Polish).

5. Stark R. M., Nicholls R. L. Mathematical fondations for design: Civil engineering systems. Mc Graw-Hill Book Company, New York, 1972. 686 p.

6. Nahmias S. Production and operations analysis. Irwin/ McGrow-Hill, Boston, 1997. 858 p.
7. Zayed T. M., Halpin D. Simulation of concrete batch plant production. $J$. of Construction Engineering and Management, Martch/April 2001, p. 132-141.

8. Warszawski A. Industralization and robotics building: $A$ managerial approach. Harper \& Row, New York, 1990. $466 \mathrm{p}$.

9. Gusakov A. A. Expert systems in the design and management of construction (Экспергные системы в проектировании и управлении строительством). Moscow: Strojizdat, 1995. 296 p. (in Russian).

10. Jaworski K. M. Metodologia projektowania realizacji budowy. Wydawnictwo Naukowe PWN. Warszawa, 1999. 480 p. (in Polish).

11. Kaplinski O. Modelling of construction processes. Komitet Inżynierii Ladowej i Wodnej PAN. Warszawa, 1997. $176 \mathrm{p}$.

12. Davis Mark M., Aquilano Nicholas J., Chase Richard B. Fundamentals of operations management. McGraw-Hill Companies, 1999. $600 \mathrm{p}$.

13. Alexouda G., Paparrizos K. A decision support system for the product line design. In: Decision Sciences Institute $5^{\text {th }}$ International Conference. Athens-Greece, July 4-7, 1999. Vol I, p. 228-230.

14. Šarka V. A decision support system applying multicriteria synthesis methods in construction. Statyba (Civil Engineering), Vol VI, No 6. Vilnius: Technika, 2000, p. 464-468.

15. Zavadskas E., Peldschus F., Kaklauskas A. Multiple criteria evaluation of projects in construction. Vilnius: Technika, 1994.

16. Neville A. M. Właściwości betonu. Polski Cement, Kraków, 2000 (in Polish).

17. Rimkus A. Public passenger transport stops optimisation. Journal of Civil Engineering and Management, Vol VIII, Suppl 2. Vilnius: Technika, 2002, p. 136-139 (in Lithuanian).

18. Masterton G. G. T. and Wilson R. A. The planning and design of concrete mixes for transporting placing and finishing. CIRA, Report 165, London, 1997.

19. Jamrozy Z. Beton i jego technologie. Wydawnictwo Naukowe PWN. Warszawa-Kraków, 2000. 484 p. 